\title{
LEAST SQUARE SUPPORT VECTORS MACHINES APPROACH TO DIAGNOSIS OF STATOR WINDING SHORT CIRCUIT FAULT IN INDUCTION MOTOR
}

\author{
M'hamed BIRAME ${ }^{1}$, Djamel TAIBI ${ }^{2}$, Sid Ahmed BESSEDIK $^{3}$, Mohamed Fouad BENKHORIS ${ }^{4}$ \\ ${ }^{1}$ LEDMASED Laboratory, University of Laghouat, 03000, ALGERIA. \\ ${ }^{2}$ Department of Electrical Engineering, Kasdi Merbah University, Ouargla, ALGERIA \\ 3 (LACoSERE) University of Laghouat, 03000, ALGERIA. \\ ${ }^{4}$ IREENA, Saint Nazaire, Polytech'Nantes, FRANCE. \\ bir_moh@yahoo.fr, taibi.djamel@yahoo.fr, s.bessedik@lagh-univ.dz, mohamed- \\ fouad.benkhoris@polytech.univ-nantes.fr
}

\begin{abstract}
Various approaches have been proposed to monitor the state of machines by intelligent techniques such as the neural network, fuzzy logic, neuro-fuzzy, pattern recognition. However, the use of LS-SVM. This article presents an automatic computerized system for the diagnosis and the monitoring of faults between turns of the stator in IM applying the LS-SVM least square support vector machine. in this study for the detection of short circuit faults in the stator winding of the induction motor. Since it requires a mathematical model suitable for modelling defects, a defective IM model is presented. The proposed method uses the stator current as input and at the output decides the state of the motor, indicating the severity of the short-circuit fault.
\end{abstract}

Keywords: (Induction Motor, Inter-turn short circuit, Fault diagnosis, least square support vector machine (LS-SVM)).

\section{INTRODUCTION}

Although the asynchronous machine is robust, it can present, like any other electrical machine, electrical or mechanical breakdowns due to heavy duty cycles, poor working environment, installation and manufacturing factors, etc. Thus, because of the important and costly consequences that the appearance of a defect can have on industrial processes, the diagnosis of faults has been the subject of growing interest for two decades.

One of the most common faults is stator winding shorted turns, which covers approximately $30 \%-40 \%$ of the overall fault conditions in IMs [1]. Therefore, fast detection techniques able to detect these kinds of faults at an early stage of evolution are particularly welcome, in order to avoid the catastrophic failure in industrial process [2].

Several techniques have been studied during the last two decades, related to the analysis of the presence of internal faults in the stator windings of induction motors. There are references to some of these techniques in [1], [3], [4].

Three main solution techniques are commonly used in the literature in order to detect shorted turns in stator windings,. The first technique is based on signal analysis, which often uses spectral tools to underline specific frequency components related to the fault [5], [6]. The second technique is related to knowledge-based approach [5], [7], [8]. The third class is based on state or parameters estimation and implies the use of mathematical models of the studied system [9], [10], [11], [12].

There has been increasing efforts dedicated in establishing AI based models to predict real-world time-dependent data. such as the Artificial Neural Network $(A N N)$, Adaptive Network based Fuzzy Inference System (ANFIS), Support Vector Machine (SVM), and Least Squares Support Vector Machine (LS-SVM). Support vector machines have been utilized as a popular algorithm realized from the machine learning [13]. The basic idea of Support Vector Machines ( $S V M)$ is to find a hyperplane in an $\mathrm{N}$-dimensional space $(N$ number of features) that differentiates classifies the data points. In order to converts not separable problem to separable problem, $S V M$ used functions called kernels which transform low dimensional data space to a higher dimensional space features. $L S$ $S V M$ is a modification of the original $S V M$ where the resulting optimization problem has half the number of parameters and the model is optimized by solving a linear system of equations instead of a quadratic programming [13-14].

In this paper, $L S-S V M$ technique is proposed for fault diagnosis and classification of the short-circuit in the stator phases of an induction machine using information provided by the stator current signature. This monitoring system will provide information on the operation of the machine to the operators who operate it. It is also able to cause in severe cases a shutdown of the machine or to allow the production system to continue to operate in degraded mode in case of problems do not require 
an immediate shutdown. The rest of this paper is structured as follows. Sections 2, 3 and 4 give a short presentation of different types of stator winding faults, modelling of a squirrel-cage induction motor with inter-turn short circuit in stator phase. Section 5 describes the $L S-S V M$ approach followed by the proposed methodology in section 6. Section 7 is devoted to simulation results and conclusion of this study is conducted in the last section.

\section{STATOR FAULTS}

In order to take into account the presence of windings of inter-turn short-circuits in the stator of an IM, an original model has been proposed in reference [11]. Figure 1 shows the defective model of the stator in the Park axes with an overall leak reported to the stator. The short-circuit current (idqcc) is represented by the equivalent fault impedance $\left[Z_{c c}\right]$ which deflects part of the stator current. By extending this model to each phase, three short-circuit impedances $\left(\left[Z_{c c 1}\right],\left[Z_{c c 2}\right]\right.$ and $\left[Z_{c c 3}\right]$ for phases $a_{1}, b_{2}$ and $c_{2}$, respectively) are added to the healthy part of the $I M$ model

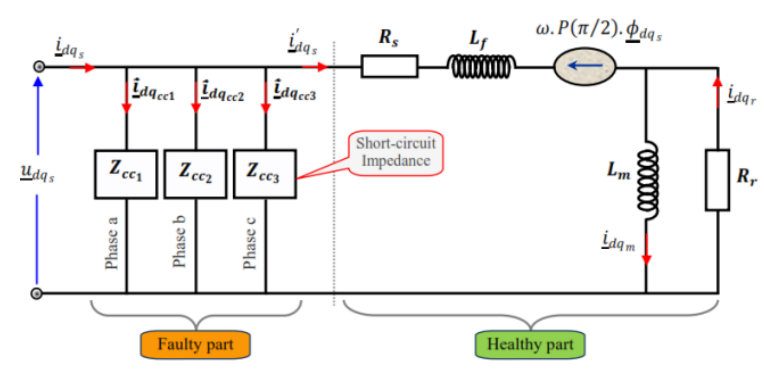

Fig. 1. Stator faulty model of induction machine

The stator fault model that we have just presented offers the advantage of explaining the fault through a resistive quadrupole dedicated to the faulty winding. The short-circuit quadrupole then responsible for explaining the fault through the two parameters $\theta_{c c}$ and $\mu_{c c}$

1. The localization parameter $\theta_{c c k}$ : This parameter can take only the three values: $0,2 \pi / 3$ and $4 \pi / 3$ corresponding to the short-circuit on the phase $a_{s}, b_{s}$, or $c_{s}$, respectively,

2. The detection parameter $\mu_{c c k}$ : is equal to the ratio between the number of inter-turn shortcircuits windings $\left(n_{c c k}\right)$ and the whole number of turns in the healthy phase $\left(n_{s}\right)$.This parameter, which allows us to quantify the unbalance, is given by:

$\mu_{c c k(\%)}=\left(n_{c c k} / n_{s}\right) \cdot 100$

\section{MODELLING OF THE ASYNCHRONOUS MACHINE "IN THE PRESENCE OF THE FAULTY"}

For the simulation, the model in the representation of the fourth order state space of the $I M$ with a winding fault is given by:

$\left\{\begin{array}{c}\dot{x}=f(x)+g \cdot u \\ y=h(x)+H(x) \cdot u\end{array}\right.$

With

$x=\left[\begin{array}{llllll}i_{d s}, & i_{q s}, \phi_{d r} & \phi_{q r} & \omega & \theta\end{array}\right]^{\mathrm{T}}:$ stat vector

$u=\left[\begin{array}{lll}u_{d s} & u_{q s} & C_{r}\end{array}\right]^{\mathrm{T}}$ and $y=\left[\begin{array}{lll}i_{d s} & i_{q s} & \omega\end{array}\right]^{\mathrm{T}}$ : machine inputs and outputs

$$
\begin{gathered}
f(x)=\left[\begin{array}{c}
-\frac{R_{s}+R_{r}}{L_{f}} \cdot i_{d s}^{\prime}+\omega \cdot i_{q s}^{\prime}+\frac{R_{r}}{L_{m} L_{f}} \cdot \emptyset_{d r}+\frac{\omega}{L_{f}} \cdot \emptyset_{q r} \\
-\omega \cdot i_{d s}^{\prime}-\frac{R_{s}+R_{r}}{L_{f}} \cdot i_{q s}^{\prime}-\frac{\omega}{L_{f}} \cdot \emptyset_{d r}+\frac{R_{r}}{L_{m} L_{f}} \cdot \emptyset_{q r} \\
R_{r} \cdot i_{d s}^{\prime}-\frac{R_{r}}{L_{m}} \cdot \emptyset_{d r} \\
R_{r} \cdot i_{q s}^{\prime}-\frac{R_{r}}{L_{m}} \cdot \emptyset_{q r} \\
\\
\frac{p^{2}}{J} \cdot\left(i_{q s}^{\prime} \cdot \emptyset_{d r}-i_{d s}^{\prime} \cdot \emptyset_{q r}\right)-\frac{f_{v}}{J} \cdot \omega
\end{array}\right] \\
g=\left[\begin{array}{ccc}
\frac{1}{L_{f}} & 0 & 0 \\
0 & \frac{1}{L_{f}} & 0 \\
0 & 0 & 0 \\
0 & 0 & 0 \\
0 & 0 & -\frac{p}{J} \\
0 & 0 & 0
\end{array}\right] \\
h(x)=\left[\begin{array}{cc}
i_{d s}^{\prime} \\
i_{q s}^{\prime} \\
\omega
\end{array}\right] \\
H(x)=\left[\begin{array}{ll}
\frac{2}{3 . R_{s}} \cdot \sum_{k=1}^{3} \mu_{c c k} \cdot p(-\theta) \cdot Q\left(\theta_{c c k}\right) \cdot p(-\theta) & 0 \\
0 & 0
\end{array}\right]
\end{gathered}
$$

\section{LEAST SQUARES SUPPORT VECTOR MACHINES}

LS-SVM is based on concepts of machinery learning. For that we establish the model on two steps:

- training

- test

In the first step, we consider a given training set [15-20] as follows:

$\{$ xi,yi $\} \in \mathfrak{R}^{2}, \mathrm{i}=1,2, \ldots \ldots \mathrm{N}$

With $x i$ input data, and $y i$ input data. Regression model is based non-linear mapping function $\phi$

$y=w^{T} \phi(x)+b$

Where $\mathrm{w}$ is the weight vector and $\mathrm{b}$ is the bias term. As in $S V M$, it is necessary to minimize a cost function $C$ containing a penalized regression error, as follows [17-20]:

$$
\min C(w, e)=\frac{1}{2} w^{T} w+\frac{1}{2} \gamma \sum_{i=1}^{N} e_{i}^{2}
$$

Subject to equality constraints:

$$
y=w^{T} \phi\left(x_{i}\right)+b+e_{i, \mathrm{i}=1,2 \ldots, \mathrm{N}}
$$


Solving this optimization problem, require Lagrange function (9). $\alpha_{i}$ are Lagrange multipliers

$$
\begin{aligned}
L(w, b, e, \alpha)= & \frac{1}{2}\|w\|^{2}+\gamma \sum_{i=1}^{N} e_{i}^{2} \\
& -\sum_{i=1} \alpha_{i}\left\{w^{T} \phi\left(x_{i}\right)+b+e_{i}-y_{i}\right\}
\end{aligned}
$$

We need to search solutions of partial derivatives with respect to $w, b$, ei and $\alpha \mathrm{i}$ which give [17-20]:

$w=\sum_{i=1}^{N} \alpha_{i} \phi\left(x_{i}\right)=\sum_{i=1}^{N} \gamma e_{i} \phi\left(x_{i}\right)$

Where a positive definite Kernel is used as follows:

$$
K\left(x_{i}, x_{j}\right)=\phi\left(x_{i}\right)^{T} \phi\left(x_{j}\right)
$$

Putting the result of (10) into (6), the following result is obtained:

$$
y=\sum_{i=1}^{N} \alpha_{i} \phi\left(x_{i}\right)^{T} \phi(x)+b
$$

For a point yi to be evaluated it is:

$$
y_{i}=\sum_{i=1}^{N} \alpha_{i} \phi\left(x_{i}\right)^{T} \phi\left(x_{j}\right)+b
$$

In addition to solve nonlinear regression it is enough to change the inner product of $\left\langle\Phi\left(x_{i}\right)\right.$, $\left.\Phi\left(y_{i}\right)\right\rangle$ (12) by a kernel function and the ijth element of matrix $K$ equals to (11)

This means as result a nonlinear regression function:

$$
y=\sum_{i=1}^{N} \alpha_{i} K\left(x_{i}, x\right)+b
$$

For a point $\mathrm{xj}$ to be evaluated it is:

$$
y_{j}=\sum_{i}^{N} \alpha_{i} K\left(x_{i}, x_{j}\right)+b
$$

For LS-SVM, there are many kernel functions (linear, polynomial, radial basis function $(R B F)$, spline, bspline, sigmoid, etc. However, the more used kernel function is RBF, a simple Gaussian function. It is defined by (16). $\sigma_{s v}{ }^{2}$ is the squared variance of the Gaussian function. It should be optimized by the user, to obtain the support vector. $\alpha$ of the $R B F$ kernel should be stressed and it is very important to make a careful model selection of the tuning parameters, in combination with the regularization constant $y$, in order to achieve a good generalized model.

$$
K\left(x_{i}, x_{j}\right)=\exp \left(-\frac{\left\|x_{i}-x_{j}\right\|^{2}}{\sigma_{s v}{ }^{2}}\right)
$$

\section{METHODOLOGY}

This section discusses the proposed methodology which includes feature extraction; Database selection and the proposed $L S-S V M$ for stator winding short-circuit fault diagnosis.

\subsection{Feature extraction}

The proposed $L S-S V M$ approach is trained and tested to identify the stator winding inter-turn short circuit fault. It evaluates the input stator current of the same phase and decides the motor condition as output by indicating the percentage of inter-turn short circuit fault occurred in the motor (Figure 2).

The input variable $\left(\operatorname{Max}\left(i_{s a}\right)\right)$ of the $L S-S V M$ algorithm represents the values of the maximum amplitude of the stator current $i_{s a}(t)$ in different working conditions of the motor. The output variable takes five values describing the indication of the short-circuits fault:

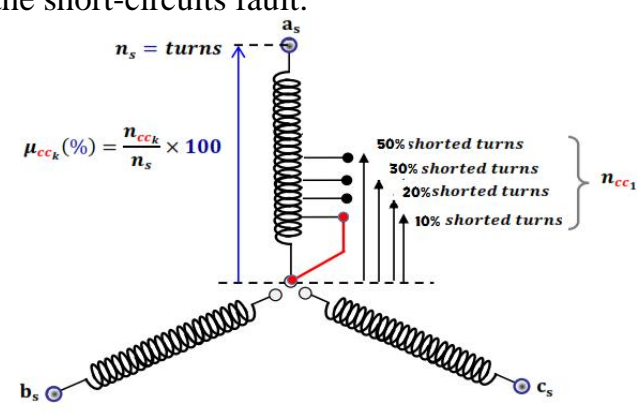

Fig. 2. Stator winding configuration with shorted turns faults

- $\quad 0:$ Healthy motor.

- $\quad$ 1: $10 \%$ shorted turns.

- 2: $20 \%$ shorted turns.

- $\quad 3: 30 \%$ shorted turns.

- 5: 50\% shorted turns.

\subsection{Database selection}

A database constituted by inputs and output data sets has been applied to train and test the $L S-S V M$ approach, the inputs-outputs data are collected through simulations in Matlab environment. The data set utilized derived from simulation are composed of 60 samples. The training set is composed of 30 samples representing the maximum amplitude of the stator current $i_{\text {samax }}$ under different load conditions $T_{L}=0,1,2,3,4$ and $5 \mathrm{Nm}$.

The test set is composed of 30 samples representing the maximum amplitude of the stator current $i_{\text {saMax }}$ under different load conditions $T_{L}=0.5,1.5,2.5,3.5,4.5$ and $5.5 \mathrm{Nm}$ are used to test its performance. Each pattern of the training and testing set comprises one input stator current signature $i_{\text {saMax }}$ and one output which represent the indication of severity of the short-circuits fault (Indic). Figure 3 summarize the process that LSSVM used for stator winding short-circuit fault diagnosis.

It is noted that, the induction machine is simulated in open-loop and the $L S-S V M$ detection method is used to evaluate the input stator current (ias) and decides the motor condition as output by indicating the severity of the short-circuits fault. 


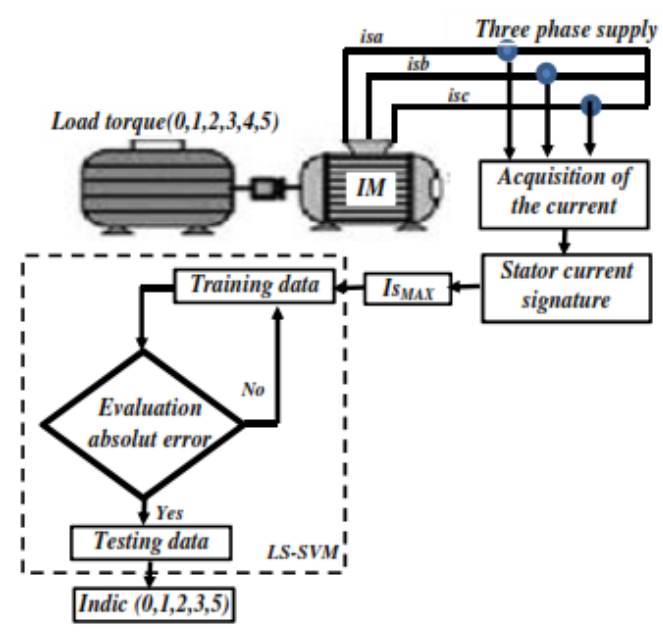

Fig. 3. Block diagram of $L S-S V M$ for stator winding short-circuit fault diagnosis

Table 1. Database for training and testing

\begin{tabular}{|c|c|c|c|c|c|}
\hline \multirow[b]{2}{*}{$c c \%$} & \multicolumn{2}{|c|}{ Training set } & \multicolumn{2}{|c|}{ Testing set } & \multirow[b]{2}{*}{\begin{tabular}{|c} 
Indication \\
(indic)
\end{tabular}} \\
\hline & $T_{L}$ & $\begin{array}{c}\text { Input } \\
\text { Max(ias) }\end{array}$ & $T_{L}$ & $\begin{array}{c}\text { Input } \\
\text { Max(ias) }\end{array}$ & \\
\hline $0 \%$ & 0 & 3,5574 & 0.5 & 3,5602 & $\underline{\mathbf{0}}$ \\
\hline $0 \%$ & 1 & 3,5775 & 1.5 & 3,6086 & $\underline{\mathbf{0}}$ \\
\hline $0 \%$ & 2 & 3,6537 & 2.5 & 3,7123 & $\underline{\mathbf{0}}$ \\
\hline $0 \%$ & 3 & 3,7841 & 3.5 & 3,8684 & $\underline{\mathbf{0}}$ \\
\hline $0 \%$ & 4 & 3,9647 & 4.5 & 4,0722 & $\underline{\mathbf{0}}$ \\
\hline $0 \%$ & 5 & 4,1903 & 5.5 & 4,3184 & $\underline{\mathbf{0}}$ \\
\hline $10 \%$ & 0 & 9,5708 & 0.5 & 9,7547 & $\underline{1}$ \\
\hline $10 \%$ & 1 & 9,9494 & 1.5 & 10,1347 & $\underline{1}$ \\
\hline $10 \%$ & 2 & 10,3357 & 2.5 & 10,5335 & $\underline{1}$ \\
\hline $10 \%$ & 3 & 10,7400 & 3.5 & 10,9522 & $\underline{1}$ \\
\hline $10 \%$ & 4 & 11,1699 & 4.5 & 11,3933 & $\underline{1}$ \\
\hline $10 \%$ & 5 & 11,6228 & 5.5 & 11,8587 & $\underline{1}$ \\
\hline $20 \%$ & 0 & 18,0303 & 0.5 & 18,2184 & $\underline{2}$ \\
\hline $20 \%$ & 1 & 18,4315 & 1.5 & 18,6132 & $\underline{\mathbf{2}}$ \\
\hline $20 \%$ & 2 & 18,8375 & 2.5 & 19,0337 & $\underline{\mathbf{2}}$ \\
\hline $20 \%$ & 3 & 19,2530 & 3.5 & 19,4834 & $\underline{\mathbf{2}}$ \\
\hline $20 \%$ & 4 & 19,7235 & 4.5 & 19,9746 & $\underline{2}$ \\
\hline $20 \%$ & 5 & 20,2383 & 5.5 & 20,5166 & $\underline{2}$ \\
\hline $30 \%$ & 0 & 26,7037 & 0.5 & 26,8866 & $\underline{\mathbf{3}}$ \\
\hline $30 \%$ & 1 & 27,1105 & 1.5 & 27,2743 & $\underline{\mathbf{3}}$ \\
\hline $30 \%$ & 2 & 27,5216 & 2.5 & 27,6961 & $\underline{\mathbf{3}}$ \\
\hline $30 \%$ & 3 & 27,9371 & 3.5 & 28,1595 & $\underline{\mathbf{3}}$ \\
\hline $30 \%$ & 4 & 28,4147 & 4.5 & 28,6888 & $\underline{\mathbf{3}}$ \\
\hline $30 \%$ & 5 & 28,9864 & 5.5 & 29,3148 & $\underline{\mathbf{3}}$ \\
\hline $50 \%$ & 0 & 44,1895 & 0.5 & 44,3518 & $\underline{5}$ \\
\hline $50 \%$ & 1 & 44,6003 & 1.5 & 44,709 & $\underline{5}$ \\
\hline $50 \%$ & 2 & 45,0148 & 2.5 & 45,1097 & $\underline{5}$ \\
\hline $50 \%$ & 3 & 45,4332 & 3.5 & 45,5751 & $\underline{5}$ \\
\hline
\end{tabular}

\begin{tabular}{|l|l|l|l|l|l|l|}
\hline $50 \%$ & 4 & 45,8556 & & 4.5 & 46,1498 & $\underline{\mathbf{5}}$ \\
\cline { 1 - 2 } \cline { 5 - 6 } $50 \%$ & 5 & 46,5135 & & 5.5 & 46,9782 & $\underline{\mathbf{5}}$ \\
\hline
\end{tabular}

\subsection{Fault detection of stator using $L S-S V M$}

As mentioned above, the database of learning inputs / outputs which based on the simulation results derived from the motor behaviour without and with faults is used to train the proposed approach and to test its performance.

Once the data is grouped, we present them as input to the $L S-S V M$ approach, the system performs its learning so that it can be ready to predict the severity of the short-circuit fault. We perform a test to validate the performance of the system by presenting as input the new data that are not part of the learning base. Once the test has been successfully completed (acceptable prediction error), the system is ready to classifier the severity of the short-circuit fault. In this paper, the parameters of $L S-S V M$ approach have been selected after several tests. Therefore, the parameters adopted for this study are: $\gamma=1000, \sigma^{2}=0.01$.

\section{RESULTS AND DISCUSSION}

\subsection{Healthy motor operation:}

The simulation of the model of the healthy machine made it possible to draw the curves of the electromechanical quantities (stator current, torque and speed) with an introduction of a resistant pair of $\operatorname{Tr}=3 \mathrm{Nm}$ at the moment $0.7 \mathrm{~s}$

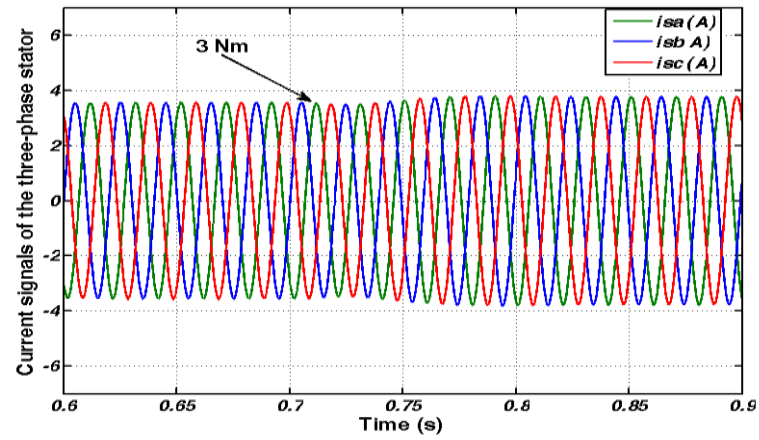

Fig. 4. Stator current of the healthy motor under load $\left(T_{L}\right.$ $=3 \mathrm{Nm}$ at $t=0.7 \mathrm{~s}$ )

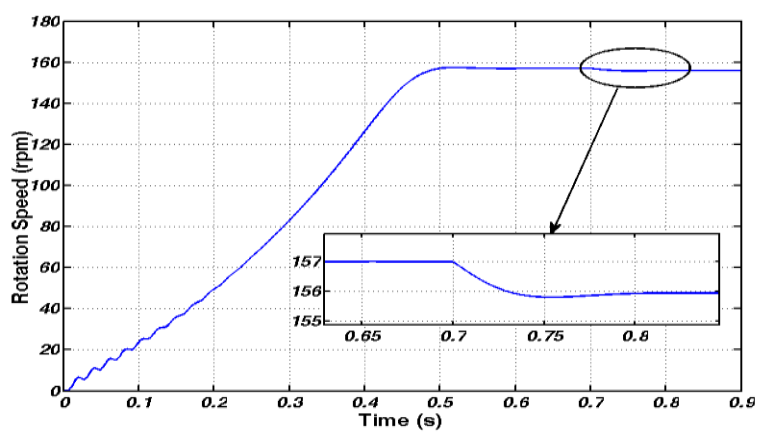

Fig. 5. Speed of rotation of the healthy motor under load $\left(T_{L}=3 \mathrm{Nm}\right.$ at $\left.t=0.7 \mathrm{~s}\right)$ 


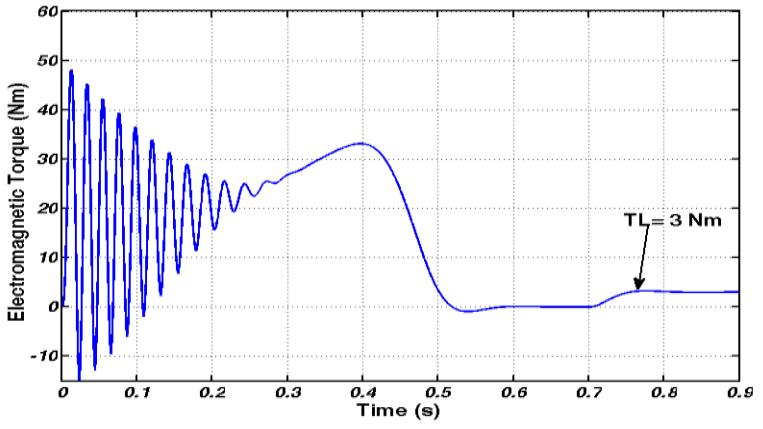

Fig. 6. Electromagnetic torque of the healthy motor under load $\left(T_{L}=3 \mathrm{Nm}\right.$ at $\left.t=0.7 \mathrm{~s}\right)$

\subsection{Operation with short circuit fault $20 \%$}

We will now present the simulation results for an operation of the $I M$ with short-circuit fault between stator turns, the degree of the short circuit is $20 \%$ at the instant of $0.9 \mathrm{~s}$.

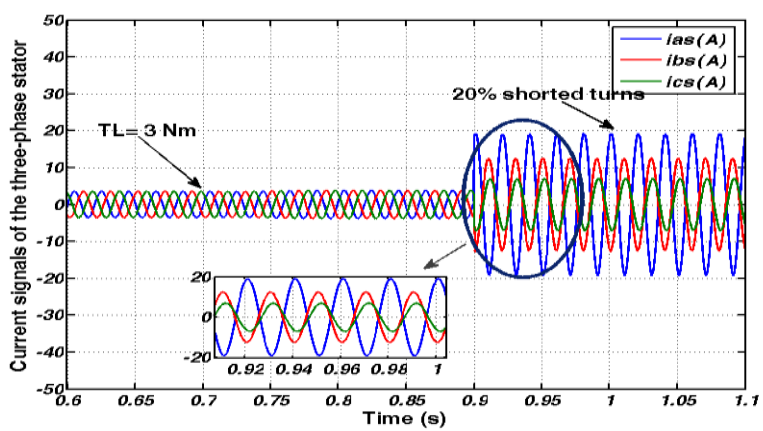

Fig. 7. Stator current motor with short circuit $(20 \%$ at $t=0.9 \mathrm{~s})$ under load $\left(T_{L}=3 \mathrm{Nm}\right.$ at $\left.t=0.7 \mathrm{~s}\right)$

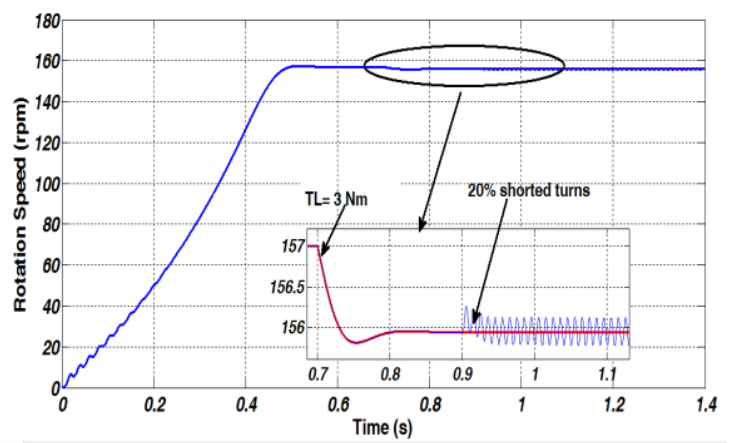

Fig. 8. Speed of rotation with short circuit $(20 \%$ at $t=0.9 \mathrm{~s})$ under load $\left(T_{L}=3 \mathrm{Nm}\right.$ at $\left.t=0.7 \mathrm{~s}\right)$

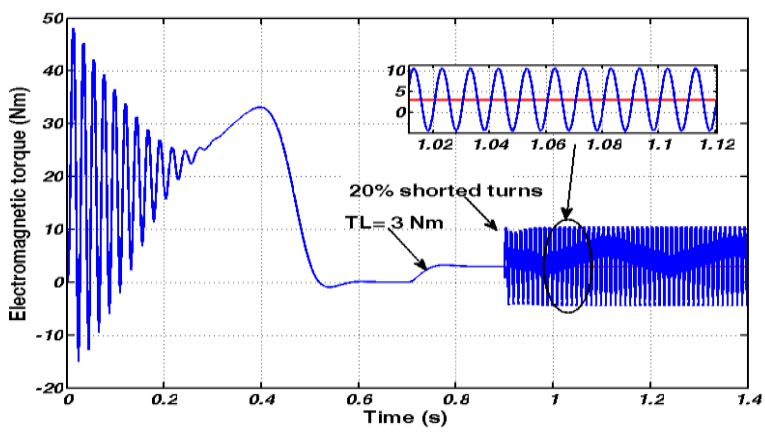

Fig. 9. Electromagnetic torque with short circuit $(20 \%$ at $t=0.9 \mathrm{~s})$ under load $\left(T_{L}=3 \mathrm{Nm}\right.$ at $\left.t=0.7 \mathrm{~s}\right)$
In the initial stage, until $t=0.9 \mathrm{~s}$, the short circuit leve is set to zero, representing a healthy $I M$ without any faults. A load torque equal to $3 \mathrm{Nm}$ is applied at $0.7 \mathrm{~s}$. A default is applied at $t=0.9 \mathrm{~s}$ $(20 \%)$. To test the severity of the fault. The fault impact appears on the stator currents (Figure 7), the speed of rotation (Figure 8) the electromagnetic torque (Figure 9), with increasing oscillations.

\subsection{Influence of short circuit fault on the stator current}

In what follows we present the simulation of the operation of the motor with short circuit of the turns of a coil with $(10 \%, 20 \%, 30 \%$ and $50 \%)$ for each load (from $0 \mathrm{Nm}$ to $5 \mathrm{Nm}$ ), to record the maximum values of the stator current

It can be revealed that, with the increase in the defect ratio of the affected phase (as) and with the increase of the load torque, the amplitude (or the $\max$ value) of the stator phase current $i_{\text {samax }}$ increases.

\subsection{Results from the LS-SVM approach}

As it has been descripted in section 6, the proposed monitoring methodology is developed to detect the stator winding inter-turn short circuit fault. The simulation results of proposed approach are shown in figures 11 and 12 respectively, in which 30 data are used to train the model and other 30 data are used to test its performance (Table 1).

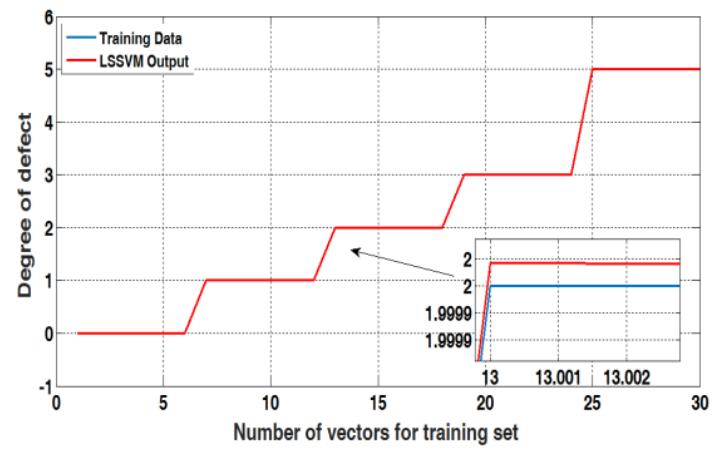

Fig. 10. Variation of degree of defect according to vector number for the training set

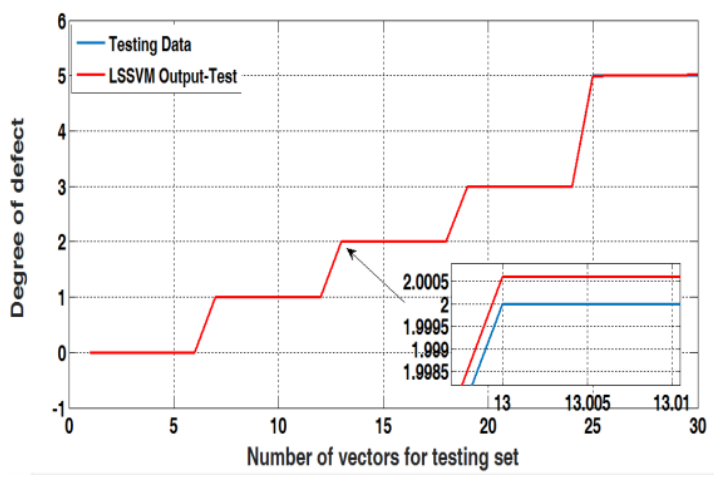

Fig. 11. Variation of degree of defect according to vector number for testing set 
From Figure 10 and 11 , it is very clear that the $L S-S V M$ algorithm gives values that are almost identical (very good adaptation) to those desired (targets). In addition, Figure 12 ( $a$ and $b$ ) displays clearly that the errors corresponding to the training and the test are very low with higher values of absolute error of 0.0118 for testing stage.

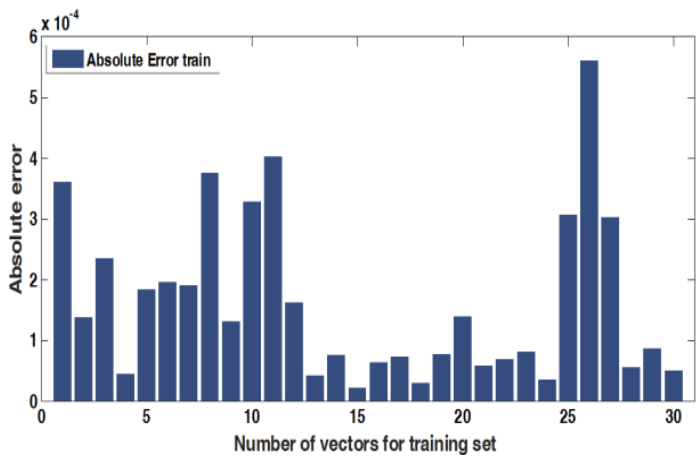

(a)

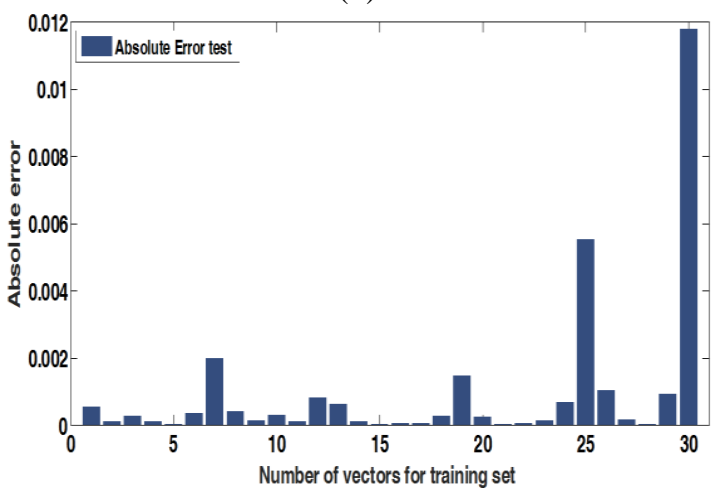

(b)

Fig.12 Curves of : a) absolute error training, b) absolute error testing

Table 2: Performance of the proposed approach

\begin{tabular}{|c|c|c|c|c|c|c|}
\hline Models & $\begin{array}{c}\text { RMSE } \\
\text { tr }\end{array}$ & $\mathrm{R}_{\text {tr }}^{2}$ & MAPE $_{\text {tr }}$ & $\begin{array}{c}\text { RMS } \\
\mathrm{E}_{\text {test }}\end{array}$ & $\mathrm{R}_{\text {test }}^{2}$ & $\begin{array}{c}\text { MAP } \\
\mathrm{E}_{\text {test }}\end{array}$ \\
\hline $\begin{array}{c}\text { LS-SVM } \\
\text { ANN }\end{array}$ & 0.0174 & .9999 & 0.3932 & .0251 & .9998 & $\begin{array}{c}0.507 \\
8 \\
\end{array}$ \\
0.1010 & .9966 & 4.6658 & .0989 & .9967 & $\begin{array}{c}4.804 \\
0\end{array}$ \\
\hline
\end{tabular}

Table 3: Machine parameters

\begin{tabular}{|l|l|}
\hline value & parameters \\
\hline $\mathrm{Rs}=2.89[\Omega]$ & Strength of a stator phase \\
\hline $\mathrm{P}=2$ & Number of pole pairs \\
\hline $\mathrm{J}=0.007[\mathrm{Kg} \cdot \mathrm{m} 2]$ & Moment of inertia \\
\hline $\mathrm{Nr}=28$ & Number of rotor bars \\
\hline $\mathrm{Ns}=464$ & Number of turns \\
\hline $\mathrm{Ls}=0.341[\mathrm{H}]$ & Stator inductance \\
\hline $\mathrm{Lr}=0.344[\mathrm{H}]$ & Rotor inductance \\
\hline $\mathrm{Un}: 220 / 380[\mathrm{~V}]$ & Nominal voltage \\
\hline $\mathrm{In}: 4,3 / 2,5[\mathrm{~A}]$ & Rated current \\
\hline $\mathrm{Nr}=1425[\mathrm{tr} / \mathrm{mn}]$ & Rated speed \\
\hline $\mathrm{Pn}=1.1[\mathrm{~kW}]$. & Nominal power \\
\hline $\mathrm{T}_{L}=7[\mathrm{~N} . \mathrm{m}]$ & Rated torque \\
\hline
\end{tabular}

Comparison of our proposed approach with other similar method as $A N N$ technique is a crucial part to evaluate the performance of the diagnostic $L S$-SVM system. The comparison is listed in Table
3 using three evaluation metrics are: Root Mean Square Error (RMSE), Mean Absolute Percentage Error (MAPE) and Correlation coefficient $\left(\mathrm{R}^{2}\right)$. These metrics are defined in reference [20].

As can be seen, the $L S-S V M$ approach have the lowest MAPE and RMSE, and higher $\mathrm{R}^{2}$ for the test set compared with ANN method.

\section{CONCLUSION}

In this paper, a $L S-S V M$ approach has been proposed as monitoring system to detect stator winding inter-turn short circuit fault of the induction motor, in which the maximum amplitude of the stator current under different load conditions is used as input variable from motor. Due to its strong generalization capability, $R B F$ kernel function is used in order to augment the generalization performance of $L S-S V M$ for classification task. The simulation shows very good adaptation based on $L S-S V M$ to the database used for the operation of training and testing. The proposed method could also be applied for other fault examination. To be able to distinguish other types of faults on the stator and / or the rotor, it will undoubtedly be necessary to add new parameters. The choice of these can be made by carrying out an analysis of the possible consequences that certain faults can generate. This is part of the perspectives of this study

\section{REFERENCES}

1. Zhang P, Du Y, Habetler TG, Lu B. A survey on condition monitoring and protection methods for medium-voltage induction motors. IEEE Trans. Ind. Appl. 2011;47:1: 34-46.

2. Gandhi A, Corrigan T, Parsa L. Recent advances in modeling and online detectionof stator inter-turn faults in electrical motors. IEEE Trans. Ind. Electron. 2011; 58(5):1564-1575.

3. Doğan Z, Selçuk R. A diagnosis of stator winding fault based on empirical mode decomposition in PMSMs. Balkan Journal of Electrical and Computer Engineering. 2020; 8(1):73-80. https://doi.org/10.17694/bajece.650484

4. Roshanfekr R, Jalilian A. An approach to discriminate between types of rotor and stator winding faults in wound rotor induction machines. Iranian Conference on Electrical Engineering (ICEE). 2018.

5. Gao Z, Cecati C, Ding SX. A survey of fault diagnosis and fault -tolerant techniques part I: fault diagnosis with model-based and signal-based approaches. IEEE Trans. Ind. Electron. 2015; 62(6): 3757-3767. https://doi.org/10.1109/TIE.2015.2417501

6. Bhattacharyya S, Sen D, Adhvaryyu S, Mukherjee C. Induction motor fault diagnosis by motor current signature analysis and neural network techniques. Journal of Advanced Computing and Communication Technologies. 2015;3(1):12-18.

7. Shifat TA, Hur J-W. An improved stator winding short-circuit fault diagnosis using adaboost algorithm. 
International Conference on Artificial Intelligence in Information and Communication (ICAIIC). 2020.

8. Dash R, Subudhi B. Stator inter-turn fault detection of an induction motor using neuro-fuzzy techniques. International Journal on Archives of Control Sciences. 2010;20(3):263-276. https://doi.org/10.2478/v10170-010-0022-7

9. Campos-Delgado DU, Arce-Santana ER, EspinozaTrejo DR. Edge optimisation for parameter identification of induction motors. IET Electr. Power Appl. 2011; 5(8):668-675.

10. Wang S, Dinavahi V, Xiao J. Multi-rate real-time model-based parameter estimation and state identification for induction motors. IET Electr. Power Appl. 2013;7(1):77-86. https://doi.org/10.1049/iet-epa.2012.0116

11. Hamoudi A, Kouadri B. Stator fault detection in induction machines by parameter estimation using trust region algorithms. Proceedings of the First. Analyses. IEEE Trans. Ind. Informatics. 2014; 10(2):1348-1360.

https://doi.org/10.15676/ijeei.2017.9.1.3

12. Melin P, Soto J, Castillo O, Soria J. A new approach for time series prediction using ensembles of ANFIS models. Expert Systems with Applications. 2012; 39(3):3494-3506.

https://doi.org/10.1016/j.eswa.2011.09.040

13. Zhang Y, Wang P, Ni T, Cheng P, Lei S. Wind power prediction based on LS-SVM model with error correction. Advances in Electrical and Computer Engineering. 2017; 17(1):3-8. https://doi.org/10.4316/AECE.2017.01001

14. Suykens J, Gestel JV, Brabanter JD, Moor BD, Vandewalle J. Least square support vector machines. World Scientific Publishers, Singapore, 2002.

15. Bu WS, Li Z. LS-SVM inverse system decoupling control strategy of a bearingless induction motor considering stator current dynamics. IEEE Access. 2019. https://doi.org/10.1109/ACCESS.2019.2939258

16. Li K, Cheng G, Sun X, Yang Z. A nonlinear flux linkage model for bearingless induction motor based on GWO-LSSVM, IEEE Access PP(99):1-1 March 2019.

17. Mahdjoubi A, Zegnini B, Belkheiri M. Prediction of critical flashover voltage of pollutedInsulators under $\mathrm{sec}$ and rain conditions using least. Squares support vector machines (LS-SVM). Diagnostyka. 2019; 20(1):49-54. https://doi.org/10.29354/diag/99854

18. Jannati M, Idris NRN, Salam Z. A new method for modeling and vector control of unbalanced induction motors. Energy Conversion Congress and Exposition (ECCE). 2012: 3625-3632.

19. Bessedik SA, Hadi H. Prediction of flashover voltage of insulators using least squares support vector machine with particle swarm optimisation. Electric Power Systems Research. 2013; 104:87-92. https://doi.org/10.1016/j.epsr.2013.06.013

20. Bessedik SA, Djekidel R, Ameur A. Performance of different kernel functions for LS-SVM-Grey Wolf Optimiser to estimate flashover voltage of polluted insulators. IET Science, Measurement \& Technology. 2018;12(6):739-745. https://doi.org/10.1049/iet-smt.2017.0486

Received 2020-07-06

Accepted 2020-11-07

Available online 2020-11-09
M'hamed BIRAME In 2005 he graduated (Magiter) with distinction at the Department of Electrical Engineering of the Faculty of Technology at Technical University in Batna. He defended his $P h D$ in the field of Power Electronics in 2015; his thesis title was "Control for speed sensorless direct torque control (DTC) applied to a variable synchronous reluctance machine $(S R M)$ use of artificial intelligence techniques“. Since 2005 he is working as Assistant Professor at Electrical Engineering Department. Laghouat University (Algeria). He is a member of the research group in LEDMASED Laboratory. His main research area includes Modeling of Electrical Machines, Electrical Drives Control, Power Electronics.

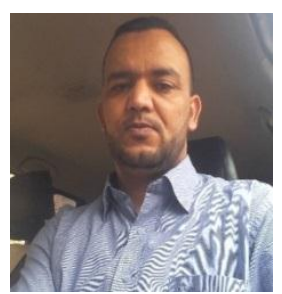

Djamel TAIBI In 2006 he graduated (Magiter) with distinction at the Department of Electrical Engineering of the Faculty of Technology. Since he is working as Assistant Professor at Electrical Engineering Department. ouargla University (Algeria). His main research area includes Modeling of Electrical Machines, Electrical Drives Control, Power Electronics, Renewable energy.

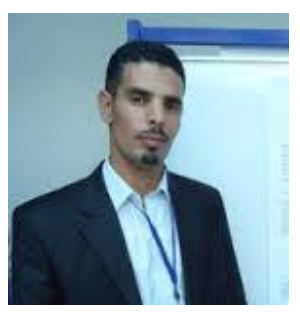

Sid Ahmed BESSEDIK received the Dipl. Ing. degrees in electrical engineering from the Univ-ersity Ibn Khaldoun Tiaret, Algeria in 2004 and Dipl. Magister in High Voltage from the University of Sciences and Technology of Oran (USTO) Algeria in 2008. Since 2010 he joined the University Amar Telidji Laghouat Algeria as assistant professor and researcher at the LACoSER laboratory. His main research interests include high voltage insulation, electromagnetic interference, fault diagnosis of induction motors, optimization methods and artificial intelligence techniques.

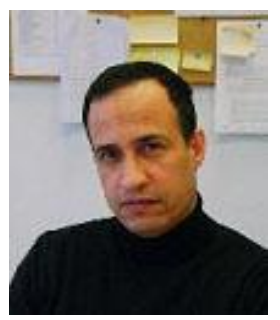

Mohamed Fouad BENKHORIS He has studied at Ecole Nationale Polytechnique d'Alger (ENPA), Algeria, and received the Engineer degree in electrical engineering (1986). In 1991 he obtained his PHD degree in electrical engineering at INP Lorraine (France) and the "HDR" (Habilitation à diriger des recherches) in March 2004. From 1991, he is a Professor at the Departement of Electrical Engineering, of Polytech'Nantes, France. Since 2006 he is Professor at Polytech'Nantes, France. He makes research activities at the laboratrory : "Institut de Recherche en Electronique et Electrotechnique de Nantes Atlantique"(IREENA) Saint Nazaire. His fields of interest are: dynamical modelling, simulation and control of electrical drives and especially multi-phase drive, multi-converters systems and embarked network. 